https://doi.org/10.34179/revisem.v6i1.14783

\title{
EXPANDINDO AS FRONTEIRAS DA IMAGINAÇÃO: ARTICULAÇÕES ENTRE LITERATURA INFANTIL E PROBABILIDADE
}

\author{
EXPANDING THE FRONTIERS OF IMAGINATION: ARTICULATIONS \\ BETWEEN CHILDREN'S LITERATURE AND PROBABILITY
}

\author{
Emilly Rayane Moura Diniz Santos \\ Universidade Federal de Pernambuco \\ emillydiniz97@hotmail.com \\ José Ivanildo Felisberto de Carvalho \\ Universidade Federal de Pernambuco \\ ivanfcar@hotmail.com
}

\begin{abstract}
Resumo
O presente estudo analisou catálogos de obras literárias com objetivos de mapear e discutir literaturas infantis que envolvam noções conceituais sobre Probabilidade. Refletimos sobre o uso da Literatura Infantil como recurso nas aulas de matemática, além de discutir o ensino de Probabilidade nos anos iniciais do Ensino Fundamental. Esse estudo analisou catálogos de 21 editoras e identificou 12 livros de literatura infantil que apresentam potencialidades para o ensino de Probabilidade e Estatística; destes, apenas 2 livros apresentaram conceitos de Probabilidade, são eles: Vamos adivinhar? (JEONG, 2010) e A aranha e a loja de balas (SO, 2011). Realizamos a exploração documental dos livros que apresentam conceitos probabilísticos, procedendo a leitura integral dos livros e investigando os conceitos de Probabilidade abordados, articulando com os pressupostos de Bryant e Nunes (2012). Esses livros apresentam narrativas envolventes, ilustrações cativantes e contextos probabilísticos pertinentes aos anos iniciais do Ensino Fundamental. Entretanto, ambos os livros apresentam diversas fragilidades conceituais sobre Probabilidade, como situações que não compreendem eventos aleatórios, representações que muitas vezes não caracterizam um correto espaço amostral, ou os diversos momentos em que as personagens tomam decisões a partir de adivinhações, opiniões ou gosto pessoal, não considerando a análise das chances pertinentes ao raciocínio probabilístico.

Palavras-chave: literatura infantil, ensino de probabilidade, anos iniciais, ensino fundamental, educação probabilística, probabilidade.
\end{abstract}

\begin{abstract}
The present study analyzed catalogs of literary works with the purpose of mapping and discussing children's literature that involve conceptual notions about Probability. We reflected on the use of Children's Literature as a resource in mathematics classes, in addition to discussing the teaching of Probability in the early years of Elementary School. This study analyzed catalogs from 21 publishers and identified 12 children's literature books that have potential for teaching Probability
\end{abstract}


and Statistics; of these, only 2 books presented Probability concepts, they are: Vamos adivinhar? (JEONG, 2010) and A aranha e a loja de balas (SO, 2011). We performed the documentary exploration of books that present probabilistic concepts, proceeding with the full reading of the

books and investigating the concepts of Probability addressed, articulating with the assumptions of Bryant and Nunes (2012). These books present engaging narratives, captivating illustrations and probabilistic contexts pertinent to the early years of elementary school. However, both books present several conceptual weaknesses about Probability, such as situations that do not include random events, representations that often do not characterize a correct sample space, or the different moments when the characters make decisions based on divinations, opinions or personal taste, not considering the analysis of the chances pertinent to the probabilistic reasoning.

Keywords: children's literature, probability teaching, elementary school, early years, probabilistic education, probability.

\section{INTRODUÇÃO}

Este artigo apresenta dados parciais, de uma pesquisa maior em andamento. Temos como objetivo analisar catálogos de editoras buscando literaturas infantis que envolvam conceitos de Probabilidade e Estatística e realizar a exploração documental nos livros que apresentam noções sobre Probabilidade a partir das demandas cognitivas de Bryant e Nunes (2012).

Este estudo se baseia na concepção de que os estudantes devem aprender "a ler matemática e ler para aprender matemática" (SMOLE; DINIZ, 2001, p. 71) nas aulas dessa disciplina. Pois, assim como defendem Smole e Diniz (2001) para ler e interpretar um texto matemático, é necessário se familiarizar com a linguagem e os símbolos para encontrar sentidos no que lê e escreve. Dessa maneira, a relação entre linguagem e matemática, através do uso da literatura infantil, permite propor questionamentos, reflexões e resolução de problemas ao longo da leitura, ao mesmo tempo envolve momentos de deleite, ativação da imaginação e ampliação do repertório literário dos estudantes. Portanto, permite a reflexão sobre as potencialidades do uso de literaturas infantis enquanto recurso metodológico para o ensino de matemática.

Nesse sentido, este artigo apresenta a discussão teórica acerca dos estudos que abordam as relações entre literatura infantil e Matemática e as potencialidades do seu uso em sala de aula, a partir dos contributos teóricos de Souza (2010), Smole (2000) e Zilberman e Silva (1990). Acerca do ensino de Probabilidade nos anos iniciais do Ensino Fundamental este estudo aborda as orientações curriculares em vigência, presentes na Base Nacional Comum Curricular - BNCC (BRASIL, 2018) e os pressupostos teóricos de 
Bryant e Nunes (2012) sobre a construção do conceito de Probabilidade a partir de demandas cognitivas básicas.

A metodologia utilizada nesse estudo é do tipo documental fundamentada por Ludke e Andre (1986) e a análise das literaturas infantis tem como aporte teórico as demandas cognitivas de Bryant e Nunes (2012). Nesse sentido, iremos proceder o mapeamento dos catálogos de obras literárias de 21 editoras, compreendendo os anos de 2016 à 2020, buscando literaturas infantis que explorem conceitos de Probabilidade e Estatística, e a análise pormenorizada das literaturas infantis que apresentam noções sobre Probabilidade, considerando as demandas cognitivas de Bryant e Nunes (2012).

\section{REFERENCIAL TEÓRICO}

\section{Literatura Infantil e Educação Matemática: potencialidades do seu uso enquanto recurso metodológico}

A literatura está presente no nosso dia-a-dia, em diversas situações e espaços do cotidiano, em momentos de aulas, da leitura antes de dormir, dos recitais, dos clubes do livro, e em diversas instituições sociais; ocupando prateleiras de bibliotecas e livrarias, até mesmo ambientes virtuais. Ouve-se falar dela nos jornais, na TV, na escola. A literatura tem suas próprias características e exigências, sendo uma experiência vivenciada pelo homem desde muito cedo, e esta experiência não se parece com nenhuma outra.

Pensando a literatura de forma ampla, Souza (2010, p. 9) concebe que

Literatura é, antes de tudo, engenharia de palavras. É por meio da palavra oral ou escrita que ela se realiza. Seu campo é vasto. Ela nasce da necessidade dos homens, desde as origens, de registrarem e compartilharem suas experiências, fantasias e, mais do que isso, valores e ensinamentos, transmitindo-as para as gerações vindouras.

Acerca da relação entre linguagem e a matemática, Smole (2000) indica que apresentam uma relação de complementariedade, no sentido de parceria; na medida em que, a matemática toma emprestada da linguagem, a oralidade, que dá suporte de significação para o aprendizado da matemática. A autora atribui à linguagem dois papéis em relação a matemática, sendo eles, 1) o estabelecimento de "relações entre o pensamento e a palavra" (p. 65), ligando as ideias matemáticas às suas representações; e 2) sua aplicação na matemática, pois os elos do raciocínio matemático estão apoiados na organização sintática e no poder dedutivo da língua. 
Acerca das maneiras de proporcionar uma relação entre matemática e língua, Smole (2000) destaca que ela pode se dar a partir do uso de "atividades que envolvem ler, escrever, falar e ouvir sobre matemática" (p. 67); apontando que dentre outras formas de potencializar a relação matemática/língua, como o uso de jornal, resolução de problemas, elaboração de textos, a conexão com a literatura infantil proporciona à criança "uma fantasia muito próxima do real, uma manifestação do sentir e do saber, o que permite a ela inventar, renovar e discordar" (p. 68). Pois compreende que essa aproximação permite a partilha de significados, além de acreditar que a literatura pode ser um modo desafiador e lúdico de desenvolver noções matemáticas.

Nesse estudo, consideramos que a presença de aspectos pedagógicos em livros infantis não diminui ou desvaloriza os atributos literários, nem o coloca em segundo plano; pois acreditamos que a presença da literatura no desenvolvimento de aprendizagens em sala de aula, bem como nas aulas de matemática, possibilita o desenvolvimento de habilidades de leitura e compreensão e de estratégias de resolução de problemas, desenvolvendo a linguagem e a matemática ao mesmo tempo. Autores como Zilberman e Silva (1990) compreendem que é possível os livros infantis trazerem consigo conhecimentos, sem perder seu aspecto literário.

Zilberman e Silva (1990) apontam que o uso dessas histórias na escola, objetiva contextualizar a aprendizagem, trazendo significado ao processo. Os autores caracterizam as histórias infanto-juvenis em três níveis, sendo eles, o caráter imaginário, que permite a narrativa extrapolar a realidade, encantando e estimulando a imaginação infantil; o dramatismo, que pelo uso da história reflete o universo infantil, permitindo que a criança vivencie sensações, muitas vezes, se identificando com a narrativa, e assim, abrindo caminho para a aprendizagem; e a linguagem, que precisa ser acessível e atraente para a criança, sendo uma característica essencial para a apreciação da história. Dessa maneira, os autores compreendem que o texto literário introduz um universo que permite ao leitor refletir e incorporar novas experiências.

\section{Ensino de Probabilidade: sua presença nos anos iniciais do Ensino Fundamental}

O principal orientador curricular brasileiro, a Base Nacional Comum Curricular (BRASIL, 2018), aponta a necessidade do desenvolvimento de compreensões 
probabilísticas e estatísticas cada vez mais cedo. A BNCC (BRASIL, 2018) apresenta objetos de conhecimento e habilidades necessárias à aprendizagem de Probabilidade e Estatística desde o $1^{\circ}$ ano dos anos iniciais, elencando habilidades para os cinco anos que compõem este nível de ensino, como apontado no Quadro 1.

Quadro 1 - Objetos de conhecimento e habilidades para o ensino de Probabilidade nos anos iniciais do Ensino Fundamental, presentes na BNCC.

\begin{tabular}{|c|c|c|}
\hline Ano & Objetos De Conhecimento & Habilidades \\
\hline $1^{\circ}$ ano & Noção de acaso & $\begin{array}{l}\text { (EF01MA20) Classificar eventos envolvendo o acaso, tais } \\
\text { como "acontecerá com certeza", "talvez aconteça" e "é } \\
\text { impossível acontecer", em situações do cotidiano. }\end{array}$ \\
\hline $2^{\circ}$ ano & $\begin{array}{l}\text { Análise da ideia de aleatório em } \\
\text { situações do cotidiano }\end{array}$ & $\begin{array}{l}\text { (EF02MA21) Classificar resultados de eventos cotidianos } \\
\text { aleatórios como "pouco prováveis", "muito prováveis", } \\
\text { "improváveis" e "impossíveis". }\end{array}$ \\
\hline $3^{\circ}$ ano & $\begin{array}{l}\text { Análise da ideia de acaso em } \\
\text { situações do cotidiano: espaço } \\
\text { amostral }\end{array}$ & $\begin{array}{l}\text { (EF03MA25) Identificar, em eventos familiares aleatórios, } \\
\text { todos os resultados possíveis, estimando os que têm maiores } \\
\text { ou menores chances de ocorrência. }\end{array}$ \\
\hline $4^{\circ}$ ano & $\begin{array}{c}\text { Análise de chances de eventos } \\
\text { aleatórios }\end{array}$ & $\begin{array}{l}\text { (EF04MA26) Identificar, entre eventos aleatórios cotidianos, } \\
\text { aqueles que têm maior chance de ocorrência, reconhecendo } \\
\text { características de resultados mais prováveis, sem utilizar } \\
\text { frações. }\end{array}$ \\
\hline \multirow[t]{2}{*}{$5^{\circ}$ ano } & $\begin{array}{l}\text { Espaço amostral: análise de } \\
\text { chances de eventos aleatórios }\end{array}$ & $\begin{array}{l}\text { (EF05MA22) Apresentar todos os possíveis resultados de um } \\
\text { experimento aleatório, estimando se esses resultados são } \\
\text { igualmente prováveis ou não. }\end{array}$ \\
\hline & $\begin{array}{l}\text { Cálculo de probabilidade de } \\
\text { eventos equiprováveis }\end{array}$ & $\begin{array}{l}\text { (EF05MA23) Determinar a probabilidade de ocorrência de um } \\
\text { resultado em eventos aleatórios, quando todos os resultados } \\
\text { possíveis têm a mesma chance de ocorrer (equiprováveis). }\end{array}$ \\
\hline
\end{tabular}

Fonte: Base Nacional Comum Curricular (BRASIL, 2018, p. 278-295)

A BNCC (BRASIL, 2018) propõe "a abordagem de conceitos, fatos e procedimentos presentes em muitas situações-problema da vida cotidiana, das ciências e da tecnologia" (p. 272). Sobre o ensino de Probabilidade, orienta o desenvolvimento da noção de aleatoriedade, possibilitando aos estudantes compreenderem os diferentes tipos de eventos aleatórios (eventos certos, eventos impossíveis e eventos prováveis), além de identificarem todos os resultados possíveis em eventos aleatórios, para além do resultado encontrado, permitindo o desenvolvimento da compreensão de espaço amostral e do cálculo de probabilidades.

Para além dos orientadores curriculares, o ensino de Probabilidade deve estar pautado nos pressupostos apontados pelos estudiosos da área. Sobre o ensino de Probabilidade, Bryant e Nunes (2012) defendem o desenvolvimento de um conjunto de conceitos para a construção dessas compreensões. Os autores elencam quatro demandas cognitivas básicas para o desenvolvimento da compreensão de situações de probabilidade, 
destacando que, apesar de cada uma dessas demandas ser diferente uma da outra, elas se inter-relacionam. A primeira demanda, a aleatoriedade, procura desenvolver a capacidade de reconhecer a incerteza dos resultados por ter elementos aleatórios envolvidos, envolvendo noções de justiça e equiprobabilidade, os diferentes tipos de eventos aleatórios, como eventos possíveis, prováveis, improváveis e impossíveis, além da independência de eventos aleatórios sucessivos. A segunda demanda, o espaço amostral, desenvolve a percepção dos alunos acerca dos possíveis eventos que formam o espaço amostral, e compreende o levantamento de todas as possibilidades. A terceira demanda, a comparação e quantificação de probabilidades, envolve o cálculo de probabilidades, que correspondem a quantidades baseadas em proporções e sendo expressas em decimais, frações ou razões, e a comparação de probabilidades que compreende a relação entre duas ou mais probabilidades. Por fim, a quarta demanda, a compreensão do risco, que se refere as relações entre variáveis, e resgata as compreensões das três demandas anteriores.

\section{METODOLOGIA}

Este estudo tem como objetivo analisar catálogos de obras literárias buscando literaturas infantis que envolvam conceitos de Probabilidade e Estatística e realizar a exploração documental nos livros que apresentam noções sobre Probabilidade a partir das demandas cognitivas de Bryant e Nunes (2012).

Para isso, este estudo tem como aporte metodológico a análise documental segundo Ludke e Andre (1986) que a define como uma técnica valiosa de abordagem de dados qualitativos, na medida em que permite complementar as informações ou desvelar novos aspectos sobre a temática investigada. Apoiados em Philips (1974), Ludke e Andre (1986) definem documentos como qualquer material escrito que possa ser usado como fonte de informação, exemplificando-se, "leis e regulamentos, normas, pareceres, cartas, memorandos, diários pessoais, autobiografias, jornais, revistas, discursos, roteiros de programas de rádio e televisão até livros, estatísticas e arquivos escolares” (p. 38).

Ludke e Andre (1986) apontam a análise documental como técnica exploratória, indicando problemas que devem ser melhor explorados, sendo os documentos fonte poderosa de evidências, de informações contextualizadas, pois surgem num determinado contexto e fornecem informações sobre o mesmo. 
Dessa maneira, se realizou o mapeamento de catálogos virtuais de obras literárias de 21 editoras, disponibilizados pelas próprias editoras em suas webpages e na plataforma issuu.com, a partir de suas páginas oficiais. Foram selecionados os catálogos mais recentes disponibilizados (correspondentes aos anos de 2016, 2017, 2018, 2019 e 2020) e categorizados a partir das unidades temáticas, eixos de conhecimento ou disciplina. Para uma melhor compreensão dos catálogos procedemos a uma leitura dos resumos apresentados por cada editora acerca dos livros, sendo eles do campo da matemática ou não. Este mapeamento buscou encontrar literaturas infantis que se proponham desenvolver conceitos sobre a unidade temática de Probabilidade e Estatística.

Ainda procedemos uma análise pormenorizada de 2 livros infantis que apresentaram compreensões sobre Probabilidade, realizando uma exploração documental pela leitura na integra dos livros infantis e investigação dos conceitos de Probabilidade abordados, articulando com as demandas cognitivas de Bryant e Nunes (2012).

\section{ANÁLISE E DISCUSSÃO DOS RESULTADOS}

\section{Análise dos catálogos de editoras e da presença de conceitos Probabilísticos e Estatísticos}

Nessa seção, discutiremos os resultados do mapeamento das literaturas infantis que envolvem conceitos de Probabilidade e Estatística; apontando que do quantitativo de livros de literatura infantil analisados, há uma baixa incidência de livros que explorem explicitamente conceitos matemáticos. Bem como, a escassez de literaturas infantis que discutam esses conceitos de Probabilidade e Estatística e de forma mais acentuada o conceito de Probabilidade.

Este mapeamento teve como objetivo conhecer literaturas infantis que tenham como proposta o desenvolvimento de compreensões probabilísticas e estatísticas; porém, consideramos na análise desses catálogos todos as unidades temáticas relacionadas à matemática, sendo elas: Números e Álgebra, Geometria, Grandezas e Medidas, Probabilidade e Estatística. A Tabela 1 apresenta a relação das editoras e da quantidade de livros observados para cada uma, de acordo com a unidade temática correspondente. 
Tabela 1 - Relação Editoras e Unidades temáticas da Matemática

Editoras

\begin{tabular}{|cccccc} 
& $\begin{array}{c}\text { Números e } \\
\text { Álgebra }\end{array}$ & Geometria & $\begin{array}{c}\text { Grandezas e } \\
\text { Medidas }\end{array}$ & $\begin{array}{c}\text { Probabilidade } \\
\text { e Estatística }\end{array}$ & Total \\
Autêntica & 0 & 0 & 0 & 0 & $\mathbf{0}$ \\
Ática e Scipione & 8 & 0 & 0 & 1 & $\mathbf{9}$ \\
Bagaço & 2 & 0 & 1 & 0 & $\mathbf{3}$ \\
Bambolê & 0 & 0 & 1 & 0 & $\mathbf{1}$ \\
Callis & 27 & 3 & 7 & 9 & $\mathbf{4 6}$ \\
Editora do Brasil & 5 & 3 & 2 & 0 & $\mathbf{1 0}$ \\
Escala educacional & 4 & 1 & 1 & 0 & $\mathbf{6}$ \\
FTD & 2 & 2 & 1 & 1 & $\mathbf{6}$ \\
Gaia & 0 & 0 & 0 & 0 & $\mathbf{0}$ \\
Gato Leitor & 0 & 0 & 0 & 0 & $\mathbf{0}$ \\
Girassol & 4 & 2 & 0 & 0 & $\mathbf{6}$ \\
Lê, Abacate, Compor & 0 & 0 & 0 & 0 & $\mathbf{0}$ \\
LeYa & 1 & 1 & 1 & 0 & $\mathbf{3}$ \\
Melhoramentos & 13 & 6 & 5 & 0 & $\mathbf{2 4}$ \\
Moderna & 16 & 0 & 0 & 1 & $\mathbf{1 7}$ \\
Nova Fronteira & 5 & 1 & 3 & 0 & $\mathbf{9}$ \\
Positivo & 6 & 2 & 3 & 0 & $\mathbf{1 1}$ \\
Rideel & 0 & 7 & 0 & 0 & $\mathbf{7}$ \\
Salamandra & 2 & 4 & 1 & 0 & $\mathbf{7}$ \\
Sei & 4 & 1 & 1 & 0 & $\mathbf{6}$ \\
SM & 3 & 2 & 0 & 0 & $\mathbf{5}$ \\
TOTAL & $\mathbf{1 0 3}$ & $\mathbf{3 4}$ & $\mathbf{2 7}$ & $\mathbf{1 2}$ & $\mathbf{1 7 6}$ \\
& & Fonte: Os autores $(2021)$. & & & \\
\hline & & & & & \\
\hline
\end{tabular}

A partir do mapeamento dos catálogos foram observados um total de 3.480 livros de histórias infantis, sendo encontrados 176 livros com temáticas relacionadas à matemática, sendo 164 destes das unidades temáticas de números, álgebra, geometria, e grandezas e medidas; a partir dos objetos de conhecimento: números, contagem, ordenação, sequenciação, operações aditivas e multiplicativas, grandezas e medidas, geometria e educação financeira. Acerca da temática de Probabilidade e Estatística foram encontrados 12 livros, sendo 2 de Probabilidade e 10 de Estatística.

Ainda se observou que apenas quatro editoras apresentaram literaturas sobre as temáticas, contando com nove livros da editora Callis, um para as editoras Ática e Scipione, FTD e Moderna. O Quadro 2 apresenta as literaturas infantis que apresentam conceitos de Probabilidade e Estatística, seus autores e editoras:

ReviSeM, Ano 2021, No. 1, p. 317-338 
Quadro 2 - Livros infantis que propõem compreensões probabilísticas e estatísticas, seus autores e editoras

\begin{tabular}{|c|c|c|}
\hline \multicolumn{1}{|c|}{ Livros } & Autores & Editora \\
\hline A aranha e a loja de balas & (Yu YeongSo) & Callis \\
\hline Vamos adivinhar? & (Cha Mi Jeong) & Callis \\
\hline Espetáculo de números & (Gilles Eduar) & Ática e Scipione \\
\hline Achem meu pai, por favor! & (Ji YunShin) & Callis \\
\hline Eu não tenho medo & (Cha BoGeum) & Callis \\
\hline Separando as coisas & (EunHee Na) & Callis \\
\hline Quando mamãe era pequena & (Hye Ok Lee) & Callis \\
\hline Quem vai ficar com o pêssego $?$ & (Yoon AhHae) & Callis \\
\hline Fugindo das garras do gato & (ChoiYunJeong) & Callis \\
\hline Como fugir do gato assustador & (ChoiYunJeong) & Callis \\
\hline O varal & (Renata Bueno) & FTD \\
\hline Vamos ao museu? & (Nereide Schilaro Santa & Moderna \\
\hline
\end{tabular}

Fonte: Os autores (2021).

\section{Exploração documental das literaturas infantis em relação as compreensões probabilísticas}

Nessa seção, trataremos sobre a exploração documental dos livros de literatura infantil que apresentam compreensões probabilísticas. Serão aqui apresentados um breve resumo sobre os livros e as compreensões probabilísticas exploradas nas literaturas infantis, discutindo algumas situações presentes nos livros que aplicam esses conceitos, destacando alguns questionamentos nessas abordagens e sua pertinência para o ensino de Probabilidade, articulando as demandas cognitivas elencadas por Bryant e Nunes (2012).

A análise dos livros Vamos adivinhar? (JEONG, 2010) e A aranha e a loja de balas (SO, 2011), proporcionou a investigação de contextos interessantes para a reflexão de como os conceitos probabilísticos estão sendo representados e aplicados em situações do cotidiano. Porém, foram identificadas diversas fragilidades conceituais sobre o conceito de Probabilidade, que serão discutidas de forma pormenorizada. 
Figura 1 e 2 - Livros Vamos adivinhar? (JEONG, 2010) e A aranha e a loja de balas (SO, 2011).
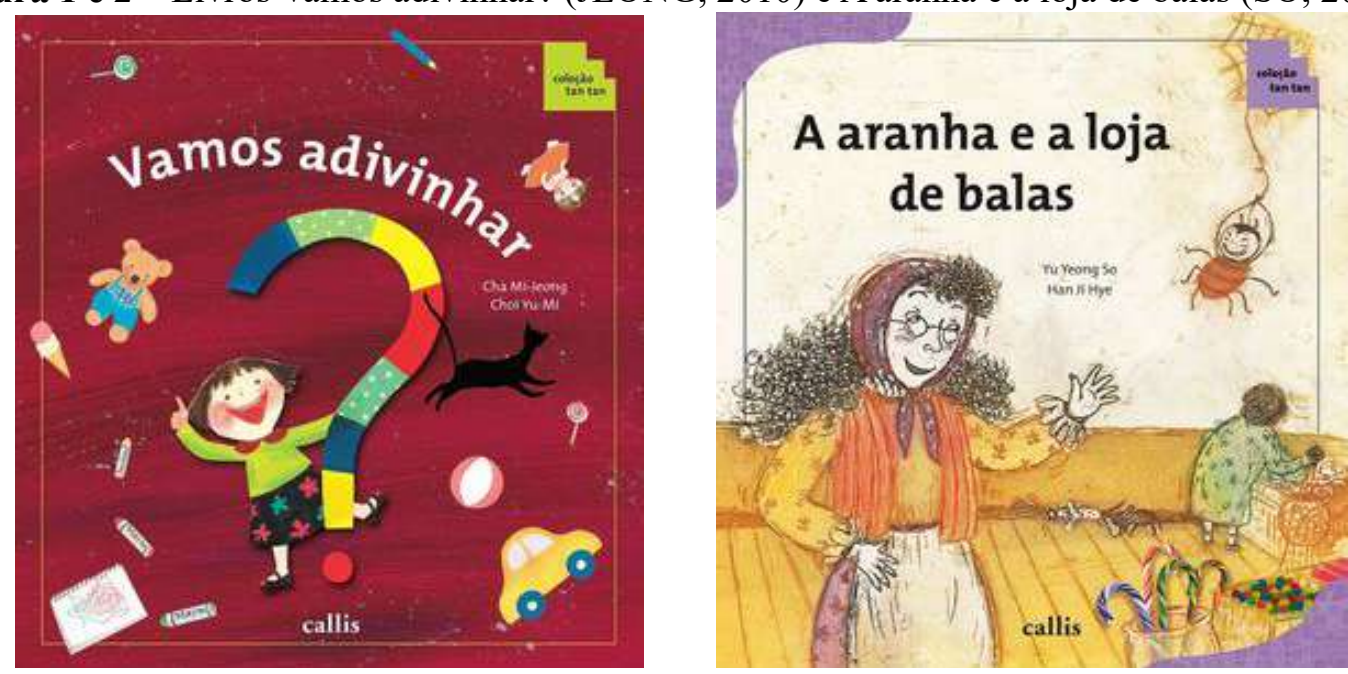

Fonte: Editora Callis.

O livro Vamos adivinhar? (JEONG, 2010) apresenta diversas situações do dia a dia de Clara e as estratégias que esta usa para prever os resultados ou tomar decisões, iniciando com a adivinhação do que irá comer no café da manhã, ou se irá chover; a previsão sobre os brinquedos que seus amigos irão comprar, bem como a escolha de um sorvete ou do jantar da sua casa, através da adivinhação, da análise das possibilidades ou da aleatoriedade, como o uso de pedra, papel e tesoura, moedas e sorteio.

Acerca da demanda cognitiva de aleatoriedade, a primeira situação a ser analisada, é a adivinhação do café da manhã, em que Clara retoma os itens comprados no mercado por sua mãe, analisando que pratos podem ser feitos com eles e o que geralmente é servido no café da manhã no dia-a-dia da sua casa. Clara apresenta uma representação do cardápio semanal do café da manhã, que assim como o texto, aponta que de segunda a sexta-feira, normalmente são servidos sanduíches e no sábado e domingo são servidos sushis. Entendemos que essa situação não se configura como evento aleatório, na medida em que se apresenta como uma rotina e depende de uma escolha pessoal ou uma preferência, não dependendo do acaso.

Nesse sentido, Bryant e Nunes (2012) apontam que a incerteza é um elemento fundamental da probabilidade, na medida em que "[...] não há um padrão discernível, nenhuma ordem definida na maneira como ocorrem e, portanto, não há certeza sobre qual será o próximo evento" (p. 16). Em situações probabilísticas podemos ter a compreensão sobre os eventos possíveis e calcular a probabilidade de cada um deles acontecer, mas não 
sabemos com certeza o que irá acontecer. Bryant e Nunes (2012) ainda salientam que as crianças precisam aprender a distinguir sequencias aleatórias de sequências não-aleatórias, entendendo as sequências de causa e efeito determinísticas para compreenderem a natureza dos eventos aleatórios.

Outro situação-problema a ser analisada é a escolha do jantar, em que Clara e sua irmã queriam jantar pratos diferentes, então imaginaram diversas maneiras de decidir de forma justa o que iriam jantar. Discute de forma correta e pertinente pontos importantes para a compreensão de aleatoriedade, a partir dos impasses provocados por Clara, que aparenta não entender a natureza justa e equiprovável das situações envolvidas, sendo elas, pedra, papel e tesoura, cara ou coroa e sorteio de papéis (com a mesma quantidade de possibilidades entre os jogadores). Nessa situação, Clara não aceita jogar pedra, papel e tesoura, porque afirma que sempre perde nesse jogo, e a irmã informa que isso se dá, porque Clara sempre coloca a mesma coisa. Como alternativa, Clara sugere jogar uma moeda, e tirar no cara ou coroa, pois na última vez que jogou ela ganhou, a irmã informa que "[...] a probabilidade de sair cara ou coroa é a mesma, metade e metade". Por fim, o pai decide realizar um sorteio para finalizar o impasse de maneira justa.

Nesse sentido, apontamos que o jogo pedra, papel e tesoura, o sorteio da moeda e de papéis (com a mesma quantidade de possibilidades entre os jogadores), se configuram como eventos equiprováveis, sendo estes, eventos em que as possibilidades tem a mesma chance de ocorrer. Esta situação ainda permite a discussão sobre a independência entre os eventos, que se caracteriza como aspecto fundamental das sequências aleatórias (BRYANT; NUNES, 2012), na medida em que, mesmo Clara tendo ganhado no cara ou coroa na última vez que jogou, isso não influencia o resultado do próximo evento, o que caracteriza os aspectos de equidade e justiça presente nos jogos aleatórios. 
Figura 3 e 4 - Situação do café da manhã e da escolha do jantar
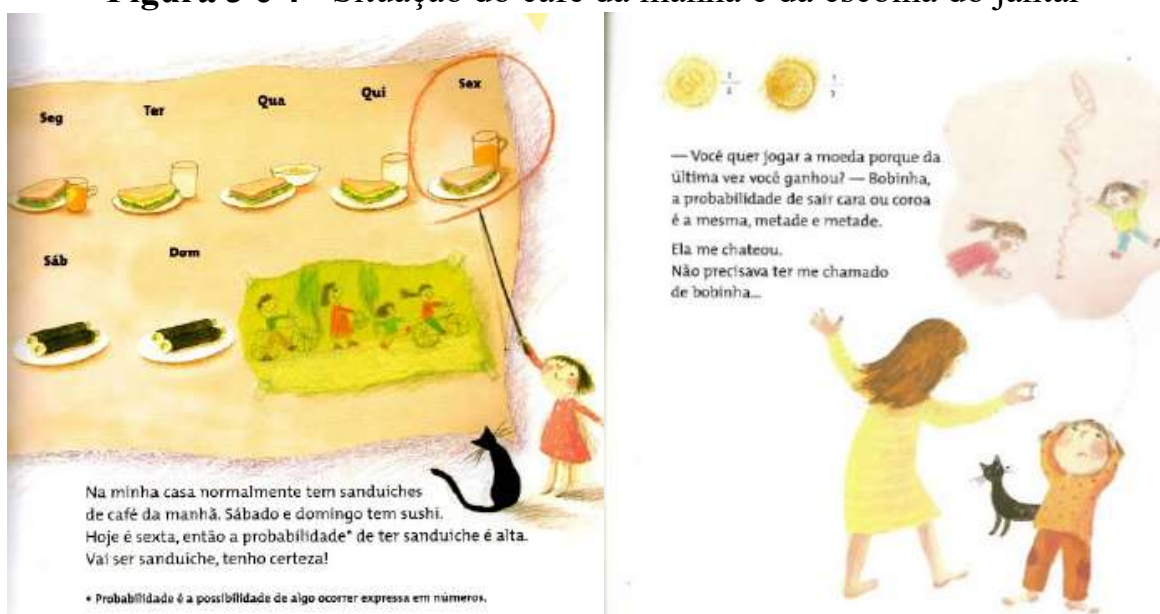

Fonte: Editora Callis (JEONG, 2010).

Sobre a demanda cognitiva de espaço amostral, será analisada a situação sobre a feira na escola, em que Clara deseja comprar uma boneca, mas tem três colegas na sua frente na fila, assim Clara tenta adivinhar o que eles irão escolher. Para justificar a adivinhação, o livro apresenta um tipo de representação que tem intenção de parecer um espaço amostral, porém não apresenta as possibilidades de eventos, e sim, os personagens e as justificativas que levam Clara à adivinhar o que os colegas irão escolher, como "Pedro é menino, então provavelmente não vai querer boneca", ou "Ana gosta de cachorros, então ela vai escolher o cachorrinho de pelúcia”; porém, essas justificativas não estão baseadas na análise das diferentes possibilidades, mas em opiniões e gostos pessoais. Bryant e Nunes (2012) apontam que espaço amostral é o conjunto de possibilidades de ocorrência de um evento em um problema de probabilidade, sendo essencial para resolver qualquer problema probabilístico, pois, a partir do levantamento de todas as possibilidades, é possível medir as chances e calcular as probabilidades de eventos particulares.

Outra situação apresentada no livro, discute a escolha de um sorvete de dois andares, a partir de três sabores diferentes (chocolate, morango e creme), representando as possibilidades de sorvetes que Clara poderia ter combinando os sabores. Esta representação caracteriza um espaço amostral, na medida em que apresenta todas as possibilidades de sorvete de dois andares, o que avança em relação as representações anteriores. Destacamos que apesar do contexto ser muito rico, o livro não apresenta uma discussão sobre o raciocínio envolvido para a realização das combinações, sendo esta uma situação que envolve o raciocínio combinatório do tipo combinação, em que "tem-se um conjunto maior 
e dele são retiradas possibilidades para formar subconjuntos, porém, [...] a ordem dos elementos não gera novas possibilidades" (PESSOA; BORBA, 2009, p. 80). O livro também não propõe situações, a partir desse contexto, que desenvolvam ideias probabilísticas, podendo ser discutido que para a composição do espaço amostral, deveriam ser combinados todos os sabores sem esquecer nenhum, esgotando todas as diferentes possibilidades, e posteriormente, realizando a discussão das chances.

Figura 5 e 6 - Situação da feira da escola e da escolha do sorvete

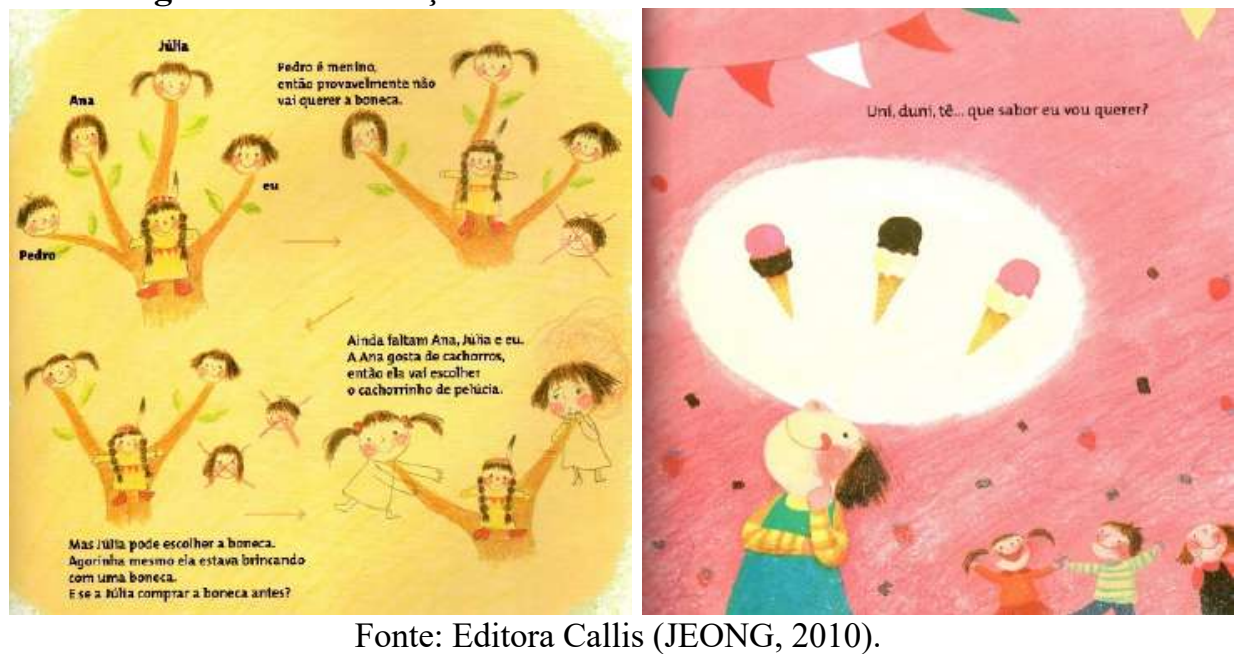

Acerca da demanda cognitiva de quantificação de probabilidades, será analisada a discussão sobre a previsão do tempo realizada por Clara e sua mãe, na qual o jornal informa que "a previsão do tempo é probabilidade de chuva é de 70\%", sobre essa afirmação, o livro explica que "[...] se tivessem 100 dias como o de hoje, em 70 deles choveria"; porém, a probabilidade de $70 \%$ de chuva, não garante uma certeza de que choverá nesse dia. Discordamos da explicação trazida no livro, na medida em que a previsão do tempo considera uma determinada chance de chuva em 100, ou seja, uma parte proporcional calculada sobre o total de ocorrências (100\%) e não 100 dias. Bryant e Nunes (2012) refletem que a probabilidade é uma quantidade intensiva porque a probabilidade de uma possibilidade particular é a proporção da quantidade de um evento particular (que se quer observar) no espaço da amostral da quantidade de eventos possíveis.

A ideia de certeza está presente em diversas situações do livro, e reforçam para o leitor que um evento mais provável ou uma alta probabilidade, indica certeza de que um determinado evento pode acontecer; essa ideia ainda é reforçada por diversas falas da 
personagem e pelo fato dela sempre estar correta nas suas adivinhações. Porém, a probabilidade de $70 \%$ de chuva, não garante uma certeza de que choverá nesse dia. Esse tipo de erro aparece em muitas situações do dia a dia, como quando a previsão do tempo indica 90\% de probabilidade de chover, e acaba sendo entendida como uma certeza de que choverá, ou mesmo quando se tem um risco muito baixo de adquirir uma infecção, muitos entendem como sendo impossível de acontecer. Entendemos que uma probabilidade alta não indica certeza, mas uma maior chance, ou uma probabilidade baixa não indica que é impossível, mas uma menor chance; assim, salientamos que a previsão do tempo nos ajuda na tomada de decisão, indicando uma chance maior ou menor de chuva, porém, não indica certeza ou impossibilidade de chover.

Após a história, o livro propõe alguns questionamentos, a primeira pergunta questiona se "Podemos saber as coisas antes delas acontecerem"; reforçando algumas atitudes e falas que associam a ideia de adivinhação ao raciocínio probabilístico, e perpassam muitas das situações-problemas do livro. Apontamos que a adivinhação não se caracteriza como pensamento probabilístico, pois a adivinhação não usa o pensamento lógico para a tomada de decisões, enquanto o raciocínio probabilístico envolve a análise lógica das possibilidades para medir as chances e a partir disso tomar decisões. Bryant e Nunes (2012) apontam que "[...] não podemos dizer o que vai acontecer nessas sequências aleatórias, mas muitas vezes podemos tentar descobrir a probabilidade de eventos particulares ou tipos específicos de eventos" (p. 29). Nesse sentido, destacamos que o uso do raciocínio probabilístico nos permite prever determinados resultados a partir da análise das possibilidades e das chances; porém não possibilita a adivinhação do resultado, mas uma previsão para uma tomada de decisão mais coerente.

O livro ainda questiona o que é probabilidade, trazendo uma explicação que aponta que "Probabilidade é conhecer a possibilidade de algo ocorrer", e ainda completa afirmando que "Se a possibilidade é alta dizemos que a probabilidade é alta" e "Se a possibilidade é baixa, dizemos que a probabilidade é baixa”. Nesse sentido, ressaltamos que durante a história aparecem conceitos de probabilidade que se assemelham a essa ideia, e apontam que "Probabilidade é a possibilidade de algo ocorrer expressa em números", porém, entendemos que probabilidade, possibilidade e chance são ideias diferentes. Para entender essa discussão, se faz necessário definir os conceitos de possibilidade, chance e 
probabilidade, sendo possibilidade, os elementos ou casos possíveis de um evento que compõem um espaço amostral; a chance, é a análise das possibilidades de ocorrência de um evento se expressando numericamente ou não; e a probabilidade, é uma percepção que se apresenta a partir de uma notação matemática formal ou de meios informais da ocorrência de eventos (GAL, 2004). Assim retomando as explicações presentes no livro, destacamos que a probabilidade é o número que mede a chance de algo ocorrer, se a chance é alta, dizemos que a probabilidade é alta, se a chance é baixa dizemos que a probabilidade é baixa.

Após os questionamentos e conceituação, o livro apresenta sugestões de situaçõesproblemas, com o mesmo contexto presente durante a história, que podem reforçar a discussão sobre Probabilidade. Essas situações, refletem sobre as chances, na medida em que se questiona quem tem a maior probabilidade de ganhar, retomando contextos como jogar uma moeda, sortear papéis e a previsão do tempo. As situações-problema de sorteio de moedas e de papeis, refletem sobre a compreensão de eventos equiprováveis, em que as chances são as mesmas. Porém, propõem um contexto em que se aumenta a quantidade de participantes do sorteio, trazendo a discussão acerca da diminuição das chances desses participantes, mas permanecendo com chances iguais entre si, na medida em que cada participante tem o mesmo número de possibilidades.

Figuras 7 e 8 - Situação da previsão do tempo e questionamentos
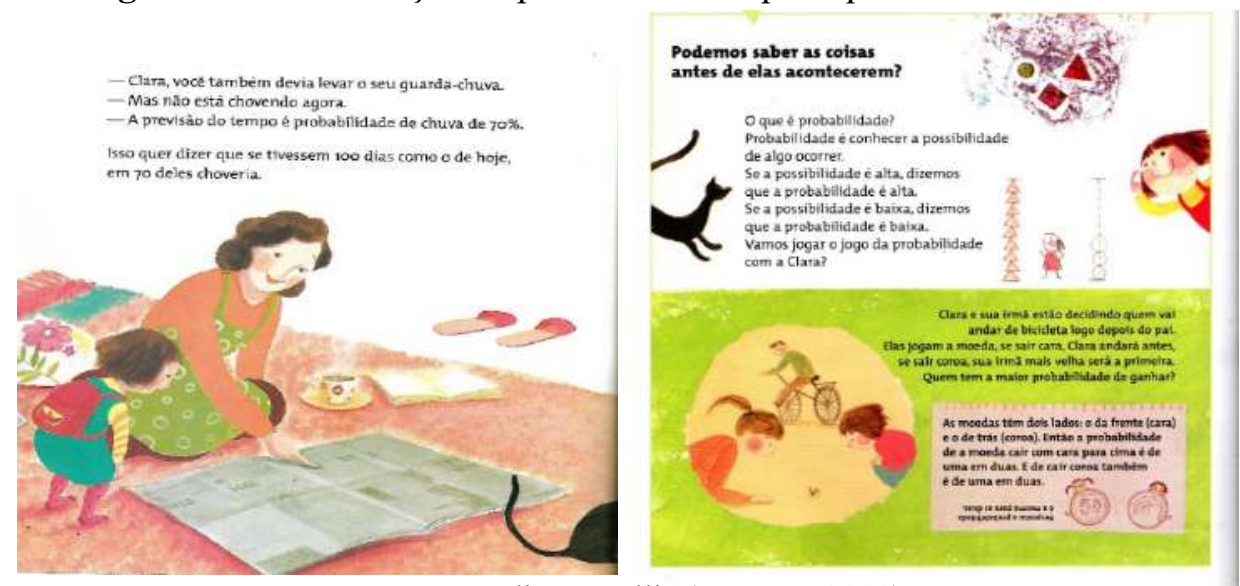

Fonte: Editora Callis (JEONG, 2010).

O livro finaliza discutindo a importância de desenvolver desde cedo nas crianças compreensões estatísticas e probabilísticas, destacando o papel das pesquisas e seus resultados na nossa vida cotidiana e de como nos auxiliam nas tomadas de decisões, apesar 
de ainda repetir alguns erros conceituais presentes no livro.

O livro A aranha e a loja de balas (SO, 2011), conta a história de uma aranha que ao ser expulsa da loja de balas onde vivia, oferece sua ajuda para adivinhar a bala que o cliente irá escolher, indicando corretamente em todas as situações a bala que o cliente comprou, a partir da análise das compras anteriores realizadas por esses clientes. Ao final, a dona da loja também realiza uma previsão da compra de uma cliente, porém acaba errando a bala que foi comprada, mesmo mapeando as compras anteriores realizadas pela cliente - assim como fez a aranha; ao que a aranha justifica a situação, informando que nem sempre se acerta.

Acerca da demanda cognitiva de aleatoriedade, o primeiro ponto a ser analisado é o uso recorrente das ideias de adivinhar e certeza, que assim como no livro anterior, perpassam todo o enredo da história. Assim como apontado anteriormente, a adivinhação não se baseia no pensamento lógico para tomada de decisões, enquanto o raciocínio probabilístico realiza a análise das possibilidades e das chances para realizar as previsões e uma tomada de decisão mais fidedigna. Sobre certeza, é possível perceber que todas as adivinhações da aranha levam ao acerto, em algumas falas ainda se usa esse termo, reforçando a ideia de certeza no resultado, na medida em que se realiza um tipo mapeamento das possibilidades (a lista de compras anteriores realizadas pelos clientes), desconsiderando a possibilidade do erro, pois o mapeamento realizado não indica certeza, mas a melhor chance. Nesse sentido, o livro reforça que escolher o item que tem mais chance, garante o acerto; porém, na probabilidade se entende que nesses casos há mais chances de acertar, mas que também é possível errar. Baseado no conceito de aleatoriedade segundo Bryant e Nunes (2012) se entende que a aleatoriedade envolve a condição de incerteza e imprevisibilidade, sendo possível elencar as possibilidades de um evento ocorrer, porém o resultado é incerto; o que difere das situações determinísticas, em que o resultado é definível e certo. Dessa maneira, a probabilidade é sempre sobre conjuntos de eventos possíveis, mas incertos, que ocorrem aleatoriamente. 
Figuras 9 e 10 - Reforço das ideias de adivinhação e certeza
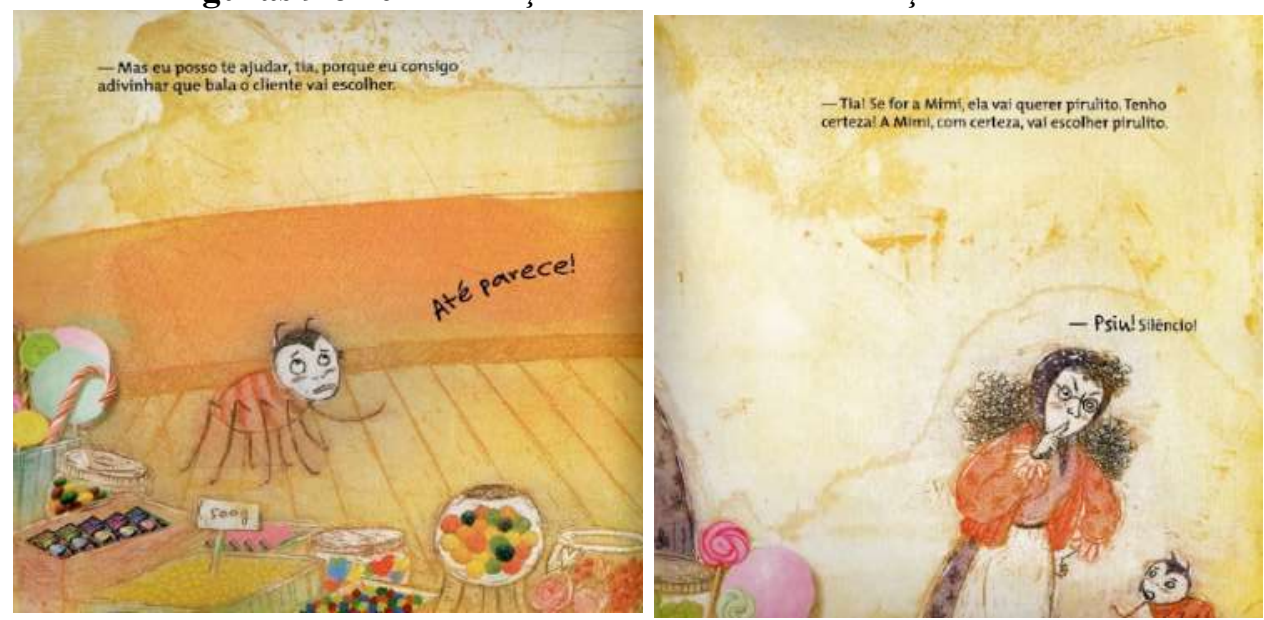

Fonte: Editora Callis (SO, 2011).

Acerca da demanda cognitiva de espaço amostral, será discutida a situação em que a aranha analisa as compras realizadas anteriormente pelos clientes, criando um mapeamento que considera apenas as preferências dos clientes para a composição do espaço amostral. Nesse sentido, se destaca que o espaço amostral deve ser composto de todos os doces da loja, para a análise dos resultados possíveis e dos resultados mais prováveis; como aponta Silva (2016), ao afirmar que “[...] o cálculo da probabilidade de um evento deve ser baseado em todas as quantidades do espaço amostral e não apenas na quantidade de eventos que desejamos prever" (p. 17). Entendemos que da maneira como está posta no livro, não é possível analisar o espaço amostral, nem afirmar o doce mais provável a ser comprado, a partir de um raciocínio probabilístico; assim, a aranha realiza a tomada de decisão através de preferencias ou gosto pessoal.

Assim como no anterior, após a história o livro traz situações-problema que utilizam o mesmo contexto presente durante a história, buscando reforçar a discussão sobre probabilidade. As duas primeiras situações-problema, apresentam o sumiço dos doces causado por ratos, em que a aranha analisa quais doces os ratos levaram anteriormente, a partir do mesmo tipo de mapeamento realizado durante a história. Nesse sentido, reforçamos a ideia de que o mapeamento apresentado no livro, não configura um espaço amostral, portanto não contribui para uma análise probabilística das chances; pois entendemos que “[...] para encontrarmos os resultados prováveis e as chances de que cada um ocorra é preciso identificar, primeiro, todos os resultados possíveis - definir o espaço amostral." (ROCHA; CARVALHO, 2014, p. 52). Ressalta-se que o texto continua a 
reforçar a ideia de certeza baseado no mapeamento da aranha; assim, reafirmamos que a análise do mapeamento ou mesmo do espaço amostral não irá indicar uma certeza do resultado, mas a melhor chance; ou mesmo escolher a possibilidade que tem mais chance, não irá garantir o acerto, pois ainda assim, existe a possibilidade de erro.

Na última situação-problema, a dona da loja de balas irá fazer mais doces, mas não sabe que doce deve fazer, assim a aranha apresenta um levantamento através de listagem dos doces vendidos em cada dia da semana, posteriormente constrói um mapeamento dos doces que mais venderam, para auxiliar na escolha do doce a ser produzido. Destacamos que o mapeamento realizado nessa situação, avança em relação aos mapeamentos anteriores se aproximando de um espaço amostral, na medida em que apresenta uma frequência de vendas; porém, ainda não apresenta o quantitativo total de doces que se têm, mas o quantitativo de doces vendidos.

Figuras 11 e 12 - Situações de mapeamento

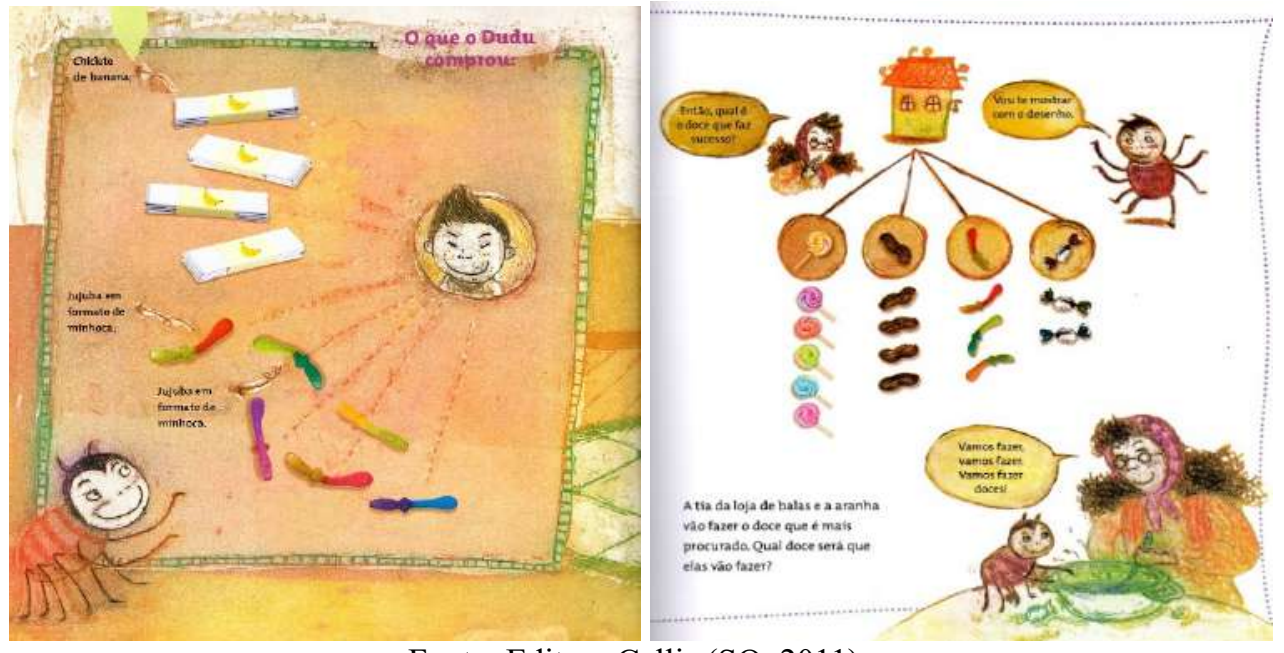

Fonte: Editora Callis (SO, 2011).

Acerca da demanda cognitiva de quantificação de probabilidades, será discutido alguns conceitos probabilísticos apresentados no livro, como o destaque da página 11, em que afirma que o fato de um cliente ter comprado pirulito nas quatro vezes em que foi a loja, significa que tem "maior probabilidade" de que ela compre pirulito novamente. Apontamos que, assim como destacado anteriormente, o mapeamento realizado pela aranha não pode ser considerado espaço amostral, pois nesse espaço amostral deveriam ser apresentados todos os doces da loja, como resultados possíveis, para depois ser analisado 
o evento mais provável ou o que tem maior chance. Sobre o espaço amostral, Bryant e Nunes (2012) apontam que é necessário realizar o levantamento exaustivo de todas as possibilidades de um determinado espaço amostral, considerando a necessidade de listar todos os eventos possíveis e eliminar qualquer elemento impossível.

Outra situação em que traz conceitos probabilísticos, se encontra na página 33, em que se apresenta uma definição de probabilidade como "[...] prever o futuro a partir dos dados coletados", porém, o termo "prever o futuro" se aproxima da ideia de adivinhação, em que se pode retomar a discussão anterior, e distancia a adivinhação do raciocínio probabilístico, considerando que a adivinhação não pensa logicamente acerca das possibilidades e das chances. O livro ainda destaca corretamente que é possível “[...] julgar se algo tem grande ou pouca probabilidade de acontecer, mas não podemos dizer que é cem por cento certo". Porém, ainda destacamos que o uso dos termos "maior ou menor chance" é mais adequado, ao invés de "grande ou pouca probabilidade".

Por fim, o livro apresenta uma sugestão de atividade, que tem como finalidade desenvolver a compreensão de Probabilidade e Estatística, através da coleta, organização e análises de dados reais. Nessa atividade, deverá ser construído uma tabela com uma frequência dos lanches preferidos das crianças envolvidas, analisando com as crianças o lanche preferido da turma. O livro ainda indica outras temáticas para esse tipo de pesquisa, como o livro preferido, o programa ou a estação do ano preferida. Analisando esta proposta de atividade, consideramos interessante a intenção de desenvolver ideias probabilísticas a partir da análise de dados estatísticos, principalmente por serem dados reais que envolvem a participação das crianças na construção, organização e análise; porém, a atividade não sugere temáticas de pesquisa que vão além das preferências pessoais. A atividade também não apresenta questionamentos probabilísticos que envolvam a noção de aleatoriedade, com perguntas que desenvolvam ideias de mais provável ou menos provável, como: "Se escolhêssemos alguém ao acaso, é mais provável que ela goste de que lanche?" ou "e se chegar mais uma criança, ela também vai preferir esse lanche?”.

\section{CONSIDERAÇÕES FINAIS}

Nesse estudo, objetivamos analisar catálogos de obras literárias buscando literaturas infantis que envolvam conceitos de Probabilidade e Estatística e realizar a 
exploração documental nos livros que apresentam noções sobre Probabilidade a partir das demandas cognitivas de Bryant e Nunes (2012). Dessa maneira, é possível afirmar que dentro do universo de catálogos mapeados e obras literárias observadas, uma pequena parcela se propõe explicitamente a desenvolver compreensões matemáticas. Além disso, destacamos que livros que envolvem compreensões sobre Probabilidade e Estatística aparecem de maneira mais tímida em relação as demais unidades temáticas, sendo os livros infantis que discutem Probabilidade os mais escassos.

Acerca dos livros infantis encontrados, estes apresentam uma boa construção narrativa, ilustrações ricas e contextos interessantes, além de discussões sobre Probabilidade e Estatística, bem pertinentes ao contexto infantil. Se faz importante destacar que apesar de estarmos discutindo livros infantis que apresentam de forma explicita compreensões probabilísticas e estatísticas, estes e outros livros, que não exploram explicitamente essas compreensões, podem possuir potencial para o desenvolvimento desses conceitos, enfim podem permitir a exploração de compreensões matemáticas.

A partir da exploração documental das literaturas infantis que trazem compreensões sobre Probabilidade, concluímos que ambos os livros apresentam potencialidades e fragilidades conceituais.

Os livros Vamos adivinhar? (JEONG, 2010) e A aranha e a loja de balas (SO, 2011), apresentam discussões sobre aleatoriedade, do espaço amostral e quantificação de probabilidades, sendo estas demandas cognitivas elencadas por Bryant e Nunes (2012) como necessárias para o desenvolvimento de compreensões sobre probabilidades. Desenvolvendo compreensões sobre eventos aleatórios equiprováveis, a partir de situações como o jogo de pedra, papel e tesoura e o sorteio de moedas e papéis; o levantamento do espaço amostral na situação de compra de um sorvete, ou mesmo analisar a frequências de compras para construir o espaço amostral; a quantificação de probabilidades na situação de previsão do tempo; além de sugerir situações problemas que envolvam a Probabilidade e a Estatística, a partir da coleta, organização e análises de dados reais. Porém, estas situações são pouco exploradas no livro e algumas apresentam fragilidades conceituais, como os erros no conceito de probabilidade e porcentagem, as representações que muitas vezes não caracterizam um espaço amostral não considerando o total de eventos possíveis, além de muitos momentos em que as personagens tomam decisões a partir de adivinhações, 
opiniões ou gosto pessoal, o que não envolve o raciocínio probabilístico. Assim, entendemos que muitas situações presentes no livro não configuram situações aleatórias, na medida em que os problemas de aleatoriedade apresentam uma condição de incerteza, para garantir a equidade e justiça (BRYANT; NUNES, 2012). Destacamos ainda, que para o desenvolvimento de ideias de aleatoriedade, espaço amostral e quantificação de probabilidades, deve ser promovida a discussão acerca das diferenças entre eventos possíveis, impossíveis, prováveis e improváveis, explorando eventos equiprováveis e não equiprováveis, além das ideias de justiça, equidade e independência de eventos, bem como o levantamento do espaço amostral que esgote todas os eventos possíveis, permitindo a análise das possibilidades e das chances para a tomada de decisão, como apontam diversos estudiosos (BRYANT; NUNES, 2012; CAMPOS; CARVALHO; 2016; SILVA, 2016); pois esses conceitos, dão base a construção da compreensão de probabilidade.

Por fim, este estudo reforça a crença de que o uso da literatura infantil nas aulas de matemática potencializa o processo de ensino-aprendizagem, na medida em que a literatura permite o desenvolvimento da imaginação e da inteligência da criança, construindo novos conhecimentos e conceitos, além de ampliar o universo literário do leitor, suas expectativas e referencias. Consideramos que a linguagem aliada a matemática contribui para a construção de conhecimentos e conceitos, desenvolvendo a organização do pensamento matemático, interpretação, contextualização e problematização, além de tornar o processo dinâmico e prazeroso.

\section{REFERÊNCIAS}

BATISTA, R.; BORBA, R. Lançando Dados e Moedas: relação de (in)dependência sob a ótica de crianças dos anos iniciais. Em Teia, v. 7, n. 1, p. 1-20, 2016.

BRASIL. Ministério da Educação. Secretaria da Educação Básica. Base Nacional Comum Curricular. Brasília, 2018.

BRYANT, Peter. NUNES, Terezinha. Children's understanding of probability: a literature review. Nuffield Foundation. 2012, 86p.

CAMPOS, T. M. M.; CARVALHO, J. I. F. Probabilidade nos anos iniciais da educação básica: contribuições de um programa de ensino. Em Teia, v. 7, n. 1, p. 1-18, 2016.

JEONG, C. M. Vamos adivinhar? Ilustração: MI, Choi Yu; Tradução: RIMKUS, Thais. 2. ed. São Paulo: Callis Ed., 2010.

LUDKE, M.; ANDRÉ, M. E. D. A. Pesquisa em educação: abordagens qualitativas. 
São Paulo: EPU, 1986.

PESSOA, Cristiane; BORBA, Rute. Quem dança com quem: o desenvolvimento do raciocínio combinatório de crianças de 1a a 4a série. Zetetike (UNICAMP), v. 17, n. 31, jan-jun, 2009b, p. 105-150.

ROCHA, C. A; CARVALHO, J. I. F. Probabilidade nos primeiros anos escolares. In: Brasil. Secretaria de Educação Básica. Diretoria de Apoio à Gestão Educacional. Pacto nacional pela alfabetização na idade certa: Educação Estatística / Ministério da Educação, Secretaria de Educação Básica, Diretoria de Apoio à Gestão Educacional. Brasília: MEC, SEB, 2014.

SILVA, Rita de Cássia Batista da. É a moeda que diz não é a gente que quer não: conhecimentos probabilísticos de crianças em situações de jogos. Dissertação (Mestrado). Universidade Federal de Pernambuco, CE. Programa de Pós-graduação em Educação Matemática e Tecnológica, 2016.

SMOLE, Kátia C. S. A matemática na educação infantil: a teoria das inteligências múltiplas na prática escola. Porto Alegre: Artes Médicas Sul, 2000.

SMOLE, Kátia C. S. DINIZ, M. I. Ler e aprender matemática. In: SMOLE, K. C. S. e DINIZ, M. I. (Orgs). Ler, escrever e resolver problemas: habilidades básicas para aprender matemática. Porto Alegre: Artmed Editora, 2001.

SO, Y. Y. A aranha e a loja de balas. Ilustração: HYE, Han Ji; Tradução: KIM, Elizabeth. 1. ed. São Paulo: Callis Ed., 2011.

SOUZA, A. A. Literatura infantil na escola: a literatura em sala de aula. Campinas: Autores Associados, 2010.

ZILBERMAN, Regina; SILVA, Ezequiel Theodoro da. (Orgs.). Literatura e pedagogia: Ponto e contraponto. Porto Alegre: Mercado Aberto, 1990. 